\title{
Numerical Analysis of Non Contact Transportation System for Wafer Warping
}

\author{
Byeong Sam KIM \\ Automotive Engineering Departement \\ Hoseo University \\ Asan City, Korea \\ kbs@hoseo.edu
}

\author{
Kyoungwoo Park \\ Mechanical Engineering Department \\ Hoseo University \\ Asan City, Korea \\ kpark@hoseo.edu
}

\begin{abstract}
This research analyzes structure of flat panel display(FPD) such as LCD as quantitative through CFD analysis and modeling change to minimize the badness rate and rate of production decrease by damage of large scale plater at wafer heating chamber at semi-conductor manufacturing process. This glass panel and wafer device with atmospheric pressure or chemical vapor deposition equipment for transporting and transferring wafers, robot hands carry these longer and wider wafers can also be easily handled. As a contact handling system composed of several problems in increased potential for fracture or warping. A non contact handling system is required to solve this problem. The panel and wafer warping makes it difficult to carry out conventional contact to analysis. We propose a new non contact transportation system with combining air suction and blowout. The numerical analysis and experimental is, therefore, should be performed to obtain compared to results achieved with non contact solutions. This wafer panel non contact handler shows its strength in maintaining high cleanliness levels for semiconductor production processes.
\end{abstract}

Keywords - flat panel display; Non contact transportation; heat treatment process; CFD

\section{INTRODUCTION}

The high-integration trend in semiconductor production processes inevitably has brought the increase of contact or contaminants generated by shock are prevented during wafer handling. This wafer hand device with atmospheric pressure or chemical vapor deposition equipment for transporting and transferring wafers, robot hands carry these longer and wider wafers can also be easily handled. As a contact handling system composed of several problems in increased potential for fracture. $300 \mathrm{~mm}$ wafer is a recent usage continues to grow. The wafer forward center of the semiconductor market is expected to be. The existing eight-inch wafer $300 \mathrm{~mm}$ wafer production is 2.5 times higher than the semiconductor chip manufacturers for $300 \mathrm{~mm}$ wafer of new processing technologies and has a lot of effort to apply. However, localization of production equipment on this lot was not built. In the field of semiconductor manufacturing technology recently developed contactless method. Non contact been emphasized that the spread of technology and floating with the development of semiconductor production equipment has been actively trying to make. The semiconductor manufacturing process technologies in the production of wafer damage wear air can be minimized by the non contact by wafer transport system that is currently used as a contact. Wafer transport system in less than a defect damage caused by increase in production meets all the essential purpose has emerged as the only alternative, and in conjunction with conventional CFD technology and its application range is wider than the optimum design and performance parts for simplification and weight reduction in non-contact method was introduced Floating.
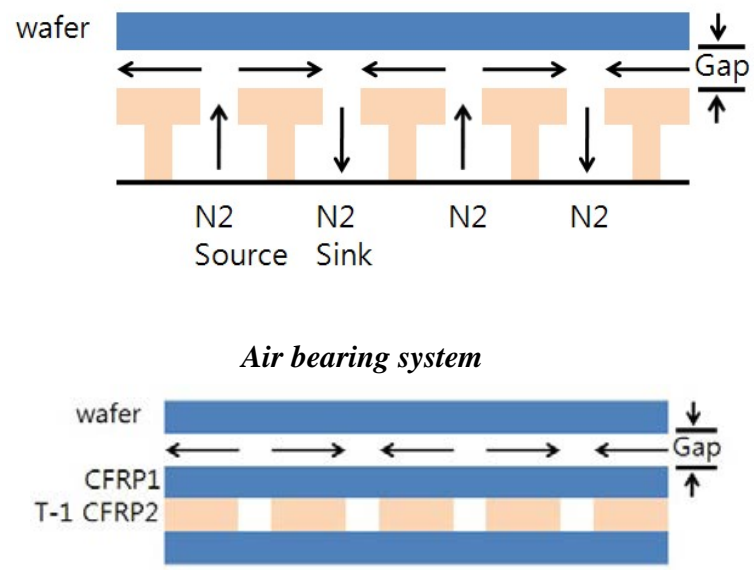

(b) Wafer hand transfer structure

Fig. 1 Air bearing system with Bernoulli's theory

In this paper, the process in step with the trend thinning spin ultra-thin wafer process development was conducted to apply. This method was applied to modern semiconductors and a representative of the trends that are increasingly smaller memory card, smart card. If the thickness of ultrathin Si wafer was used thinning process to create ultra-thin, when the device's mechanical and electrical resistance sharply increases 
the likelihood of irreversible damage, Wafer because of the difficulty in handling the process is important in developing a systematic approach. Thinning process recently, dicing, and surface treatment processes, as well as de-tape process, and surface characterization equipment coming out, as far as possible, but accuracy, efficiency, yield, reliability, etc. are still there remains a problem to be solved. Examples of ultrathin wafer warpage or chipping instantly solve the problem. if it is also important processes inside a connection-handling systems, and process equipment necessary for the precise design process can be seen especially in the process of wafer to wafer transfer occurs when the pollution or damage reducing to a minimum to discourage bad or disposal. In addition, stacked package and IC card used in the field, and this development will be applied in the process of $300 \mathrm{~mm}$ Wafer.

\section{WAFER ANALYSIS}

\section{A. Air Bearing Theory}

The wafer weights consisted by pressure force $P$ with air suction and blowout. The air balance designed to be able to maintain the gap with wafer weight. Accordingly, the source of the atmospheric pressure $\left(\mathrm{P}_{\mathrm{v} 1}\right)$ when sent out to the discharge pressure $\left(\mathrm{P}_{\mathrm{v} 2}\right)$ was designed by calculating the difference, the equation (1) is calculated by hole diameter of $A_{V} \infty$ and that of integrated $P$ and $r$-value greater than the total mass of the wafer handling when you reach wafer principle that non contact was used.

$$
A_{s} P_{r r} \int_{\theta_{r}}^{A_{r}} \int_{\theta_{r}}^{A r} P(r, \theta) d r d \theta \geq W_{f}
$$

The non-contact wafer processes of semiconductor manufacturing equipment propose to the development using air bearing principle with air suction and blowout. The default condition at room temperature/atmospheric pressure-driven SEMI-compliant and related to maintaining a non-contact and adsorption force that satisfy the conditions while maintaining constant pressure on wafer deformation does not occur the way that satisfies the initial conditions were used.

\section{B. Structure of Wafer Handling System}

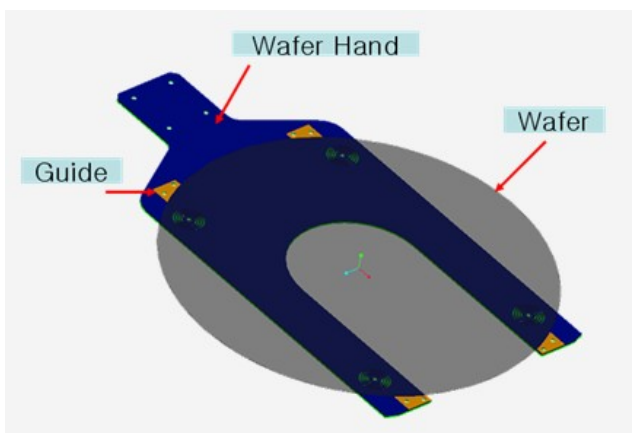

Fig. 2 Wafer hand modeling of upper hand plate, under hand plate and wafer guide(Pro-E)

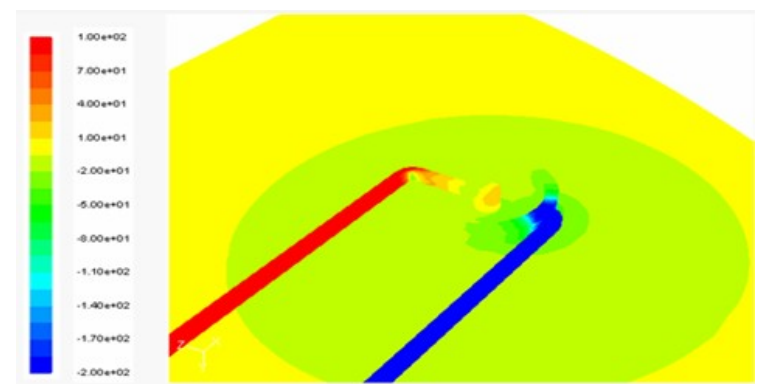

Fig. 3 Contours of static pressure of wafer hole and u line (FLUENT)

Contactless wafer technology to use in the basic concepts of non-contact as shown in Fig 3 jet of air pressure to the support, according to the wafer by wafer transfer by minimizing contact with is the concept that you want to use.

B. CFD Analysis

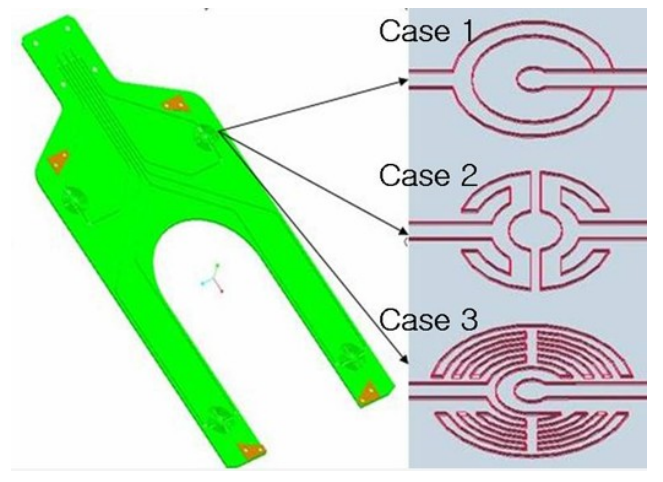

Fig. $4 \mathrm{U}$ Line and hole for the different cases with air bearing principle

Wafer fabrication of hand prior to analysis using CFD flow analysis to compare the changes in structural design using 3D tool air hole, and three points for each Case CFD analysis using FLUNT commercial software to design and due to the pressure rise / change in the state of adsorption was investigated. The design of the hand rail wafer hand existing for the purpose of optimal design based on the track and the pressure within the constant as shown in Fig 4 that the points in order to reduce the unnecessary computation time air hole, as shown in Fig 4 by splitting off a portion of the design was carried out. Contactless wafer design of the track, which is the core part of the hand rail and the support or due to adsorption conditions have two kinds of pressure, so that you can emerge outlet/inlet line and off line configuration and to reduce the damage of wafer air hole includes a modular design. In each case in part by air hole, especially the pressure to investigate the behavior of three kind's type was designed.

TABLE 1 MODELING OF WAFER FOR DIFFERENCE CASE

\begin{tabular}{|l|c|c|}
\hline & Diameter $(\mathrm{mm})$ & Thickness $(\mu \mathrm{m})$ \\
\hline Case 1 & 300 & 70 \\
\hline Case 2 & 300 & 775 \\
\hline Case 3 & 300 & 775(aluminum)+70(Wafer) \\
\hline
\end{tabular}


In this paper, the support in order to wafer as Fig 4 upper hand plate, under hand plate is separated to prevent the peace. The wafer guide was applied to the process used in wafer gap basis according to the thickness of $300 \mathrm{~mm}$ wafer through the optimal design to identify and wafer stable and reliable transport system was developing. Also wafer thinning processes developed by combining non-contact on hand immediately proceed to commercialization was designed to do. Depending on the thickness of the non-contact wafer when transported in accordance with the pressure applied to wafer investigate the variation of the following cases was designed for each model.

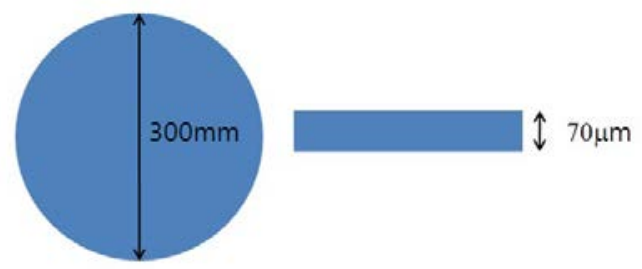

(a) Case 1 model (Silicon)

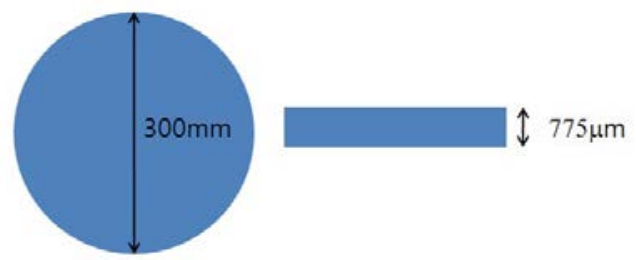

(b) Case 2 model (silicon)

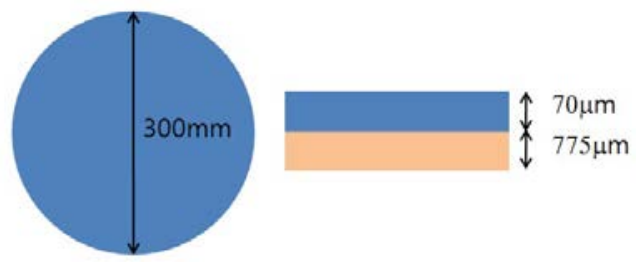

(c) Case 3 model (Aluminium and Silicon)

Fig. 5 Wafer model in each cases

TABLE 2 RESULTS OF MAXI/MIN. PRESSURE

\begin{tabular}{|c|c|c|}
\hline & $\begin{array}{c}\text { Maximum } \\
\text { Pressure(pascal) }\end{array}$ & $\begin{array}{c}\text { Minimum } \\
\text { Pressure(pascal) }\end{array}$ \\
\hline Case 1 & $4.00 \mathrm{e}+01$ & $-3.00 \mathrm{e}+01$ \\
\hline Case 2 & $5.00 \mathrm{e}+01$ & $-1.00 \mathrm{e}+02$ \\
\hline Case 3 & $1.61 \mathrm{e}^{+}+02$ & $-2.00 \mathrm{e}+02$ \\
\hline
\end{tabular}

Contactless wafer transfer technology of design requirements were defined and analyses. Wafer thickness $\mathrm{t}=$ $70 \mu \mathrm{m}$ non contact when the diameter of $\varphi 300 /$ adsorption pressure conditions due to variations in the two possibilities are analyzed in thinning processes. CFD analysis was checked the suction pressure in the recipient's first when wafer hand analysis was conducted for the pressure distribution. Pressure line was defined $1.5 \mathrm{~mm}$ line width of the size of $1 \mathrm{~mm}$ vertical line by setting the initial value.

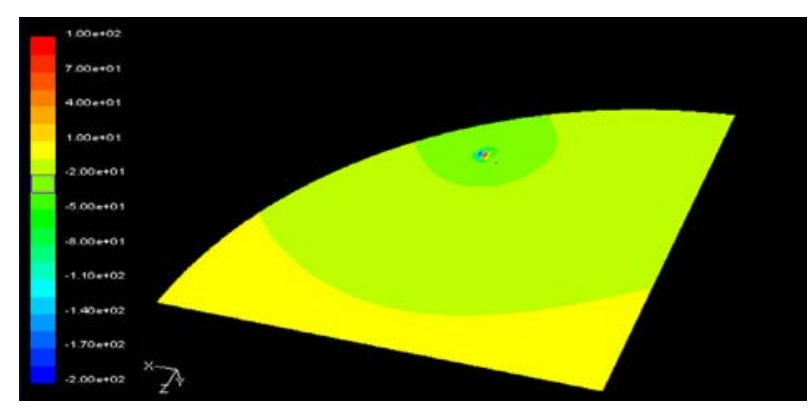

Fig. 6 Optimized model for minimum non contact condition using CFD analysis (FLUENT)

Wafer based on 1/4 section on the suction line cross section of $20 \mathrm{~m} / \mathrm{s}$ in the support section of the track air speed $20 \mathrm{~m} / \mathrm{s}$ were to enter in the suction. In addition, based on the results of analysis under pressure in the distribution of wafer hand analysis was conducted based on the optimal results in Table 3 are as wafer deformation due to pressure on the recipient in order to determine the amount of structural analysis using the ABAQUS 5.6 analysis was conducted resulting from hand pressure was set to the same conditions for wafer damage.

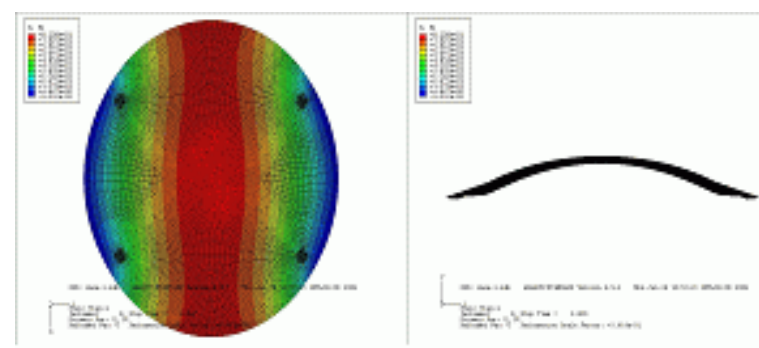

Fig. 7 Wafer damage of Case 1 with suction pressure

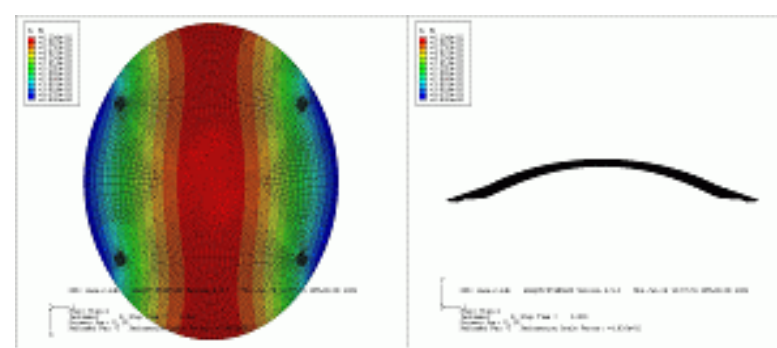

Fig. 8 Wafer damage of Case 2 with suction pressure

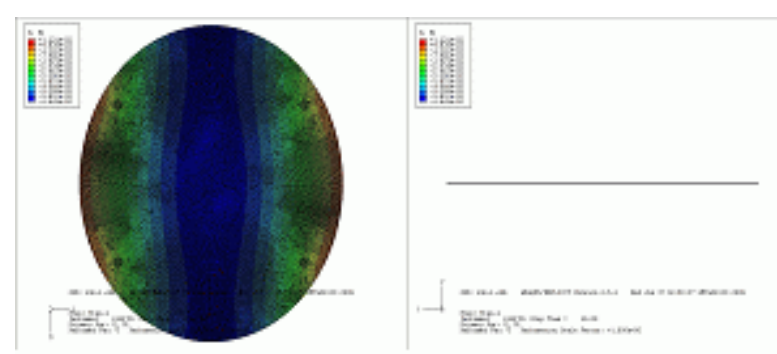


Fig. 9 Wafer damage of Case 3 with suction pressure

TABLE 3 PRESSURE OF INLET PRESSUREAND OUTLET FOR WAFER SURFACE

\begin{tabular}{|c|c|c|}
\hline & Inlet pressure(pascal) & Outlet pressure(pascal) \\
\hline \multirow{3}{*}{ Wafer } & \multirow{3}{*}{-200} & -50 \\
\cline { 3 - 3 } & & 40 \\
& & 10 \\
\hline
\end{tabular}

\section{RESULTS AND DISCUSSION}

\section{A. CFD Results}

As shown in Table.2 by each case shows the maximum pressure and minimum pressure. Hand hole appeared about three kinds of case under optimal pressure distribution on wafer by case 1 . Table.3 as a set from the inside to the outside pressure was set by dividing the distribution. Case 3 CFD flow analysis of flow distribution and pressure is shown in Fig. 9 and Fig. 11 wafer are distributed evenly. Based on the maximum pressure and minimum pressure under pressure by typing in wafer and using the ABAQUS 5.6 structural analysis was carried out by each case. Through structural analysis results shown Fig.7, Fig.8, Fig.9, and the same maximum deformation happens in wafer damage through suction pressure for a change in the direction shown in the Table 4.
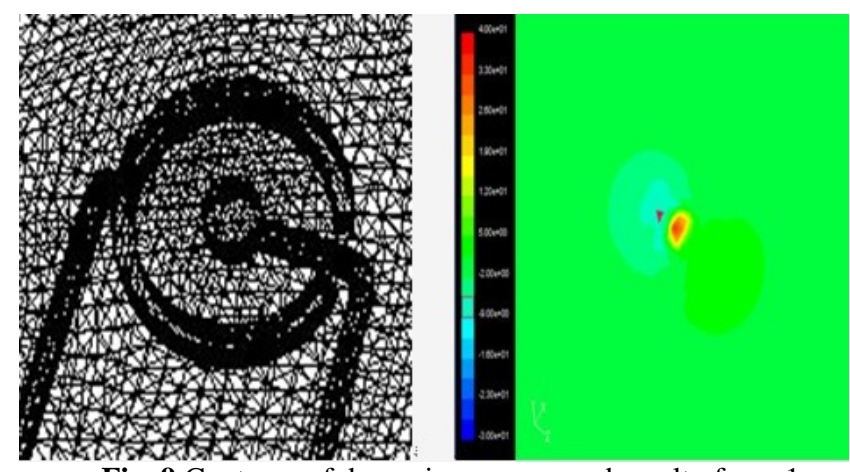

Fig. 9 Contours of dynamic pressure and result of case1 analysis(FLUENT)
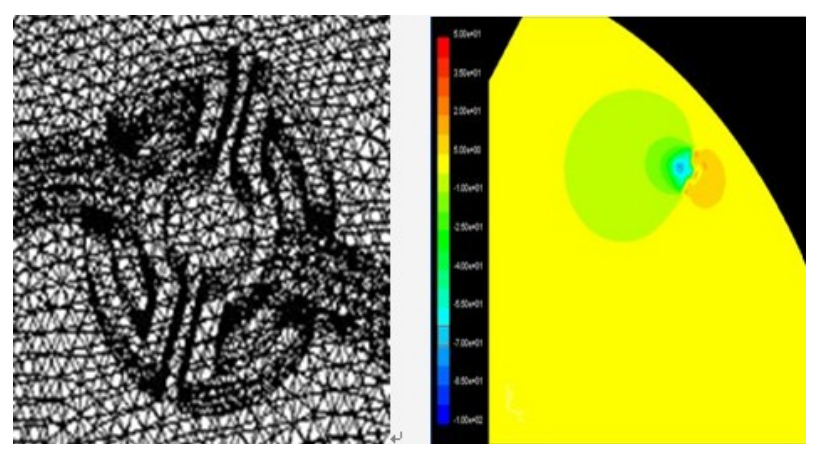

Fig. 10 Contours of static pressure and result of case2 analysis(HYPER-MESH, FLUENT)
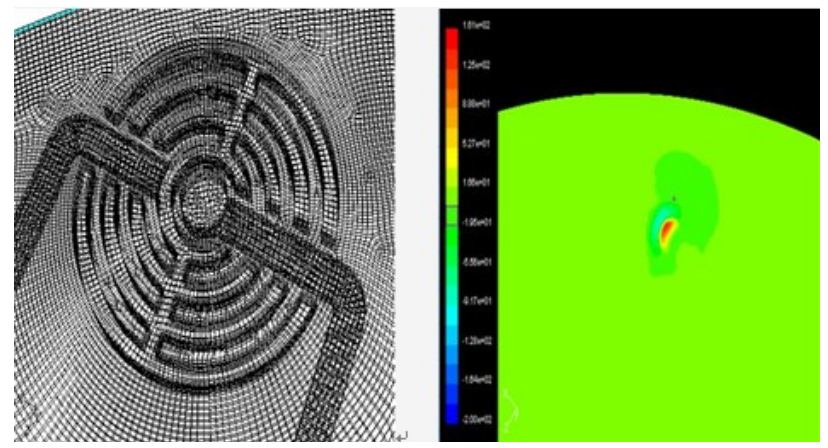

Fig. 11 Contours of static pressure and result of case3 analysis(HYPER-MESH, FLUENT)

TABLE 4 RESULTS OF MAXIMUM DISPLACEMENT AND MINIMUM DISPLACEMENT FOR DIFFRENCE CASES

\begin{tabular}{|l|c|c|}
\hline & $\begin{array}{c}\text { Maximum } \\
\text { displacement }(\mathrm{mm})\end{array}$ & $\begin{array}{c}\text { Minimum } \\
\text { displacement }(\mathrm{mm})\end{array}$ \\
\hline Case 1 & $8.299 \mathrm{e}+01$ & $-5.332 \mathrm{e}-02$ \\
\hline Case 2 & $6.204 \mathrm{e}-02$ & $+5.170 \mathrm{e}-03$ \\
\hline Case 3 & $1.131 \mathrm{e}-02$ & $-6.465 \mathrm{e}-02$ \\
\hline
\end{tabular}

Contours of dynamic pressure through case, air behavior and the maximum stress, minimum stress by comparing the structure of the optimal design of case can make. As a Fig. 7 can be found at case 3 to determine the contours of pressure, and Table 2 through the maximum, minimum pressure, the stress distribution depending on the type of hole through the air have confirmed that the behavior varies. Through the CFD analysis for each case flow distribution by wafer in table 2 under the pressure and flow distribution in the best when considering the structural design of the model have confirmed that case 1 appeared. In addition, as shown in Table 4 based on the results of flow analysis conducted by the structural analysis of wafer divided into three kinds of thickness of each strain were obtained.
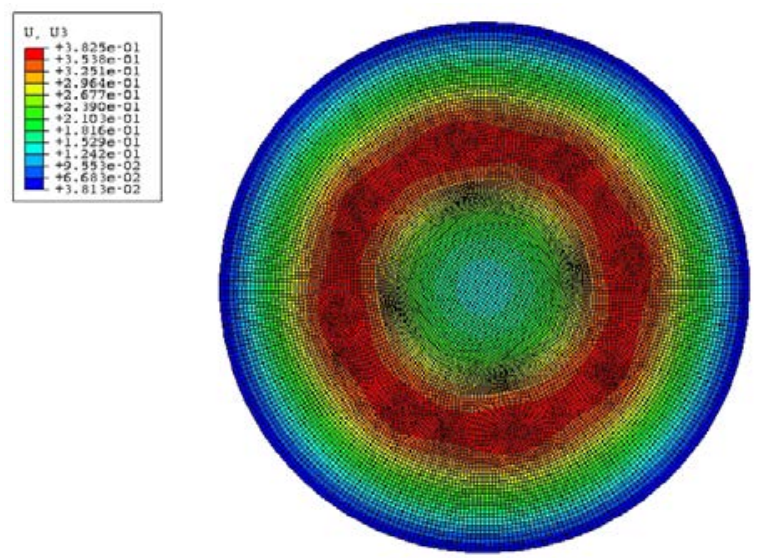

Fig. 12 Wafer analysis by Case wafer displacement(ABAQUS 5.7) 


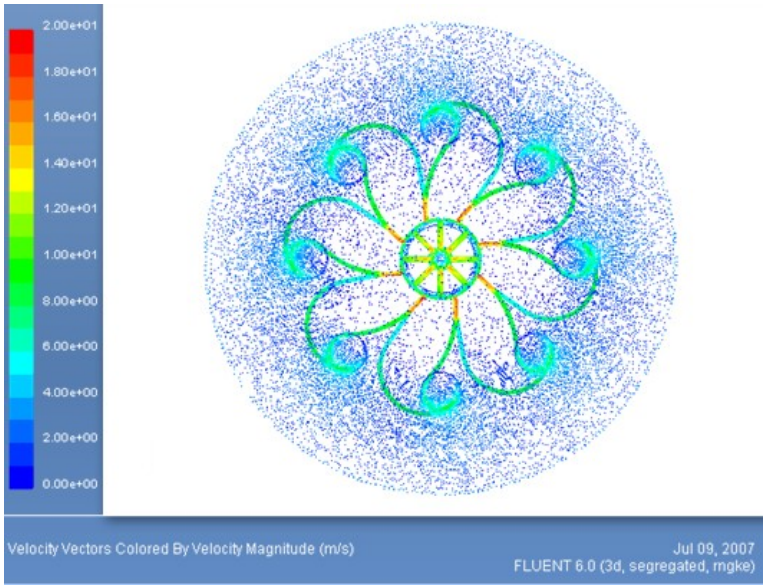

Fig. 13 Wafer chuck analysis with pressure (upper side) and Velocity (under side) with Fluent

Fig 4, as the condition was due to each case in the form of a thin film silicon diameter of $300 \mathrm{~mm}$ wafer thickness is 70 . The other case 2 used in the traditional format with a thickness of $700 \mathrm{~mm}$ silicon is the material of $300 \mathrm{~mm}$ wafer. Last case 3 to solve the problem of the Case 1 on aluminum wafer silicon wafer thin film in the form that is loaded with only one way to appear when the problem is security. Be applied to the analysis of gases was applied to the air mesh using a CFD analysis program was analyzed using Fluent. Wafer thinning process commercially available weight about $226 \sim 260 \mathrm{~g}$, thickness $\mathrm{t}=70 \Phi=300 \mathrm{~mm}$ diameter initial velocity $100 \mathrm{~m} / \mathrm{s}$ when the injury / adsorption potential due to variations in pressure conditions were analyzed.
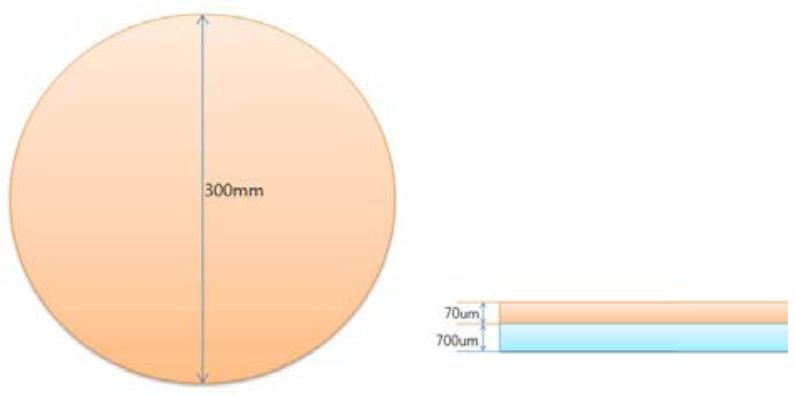

Fig. 14 Wafer model in cases (Aluminum and Silicon)

TABLE 5 DIFFERRENCE WITH WAFER IN EACH CASE

\begin{tabular}{|c|c|c|c|}
\hline & Material & um Thickness [] & Diameter [mm] \\
\hline Case1 & Silicon & 70 & 300 \\
\hline Case2 & Silicon & 700 & 300 \\
\hline Case3 & Silicon & 70 & 300 \\
\hline
\end{tabular}

\begin{tabular}{|l|l|l|l|}
\hline & Aluminum & 700 & 300 \\
\hline
\end{tabular}

\section{B. Results of Structural Analysis}

Case 2 and case 3 type thin-film wafer, 6 inch wafer and thin film on top of the aluminum plate is a state place. Case 2 is the first case of displacement U- line, displacement $-0.05332 \mathrm{~mm}$ at $+8.299 \mathrm{~cm}$ is shown that variations from. These results in a large strain large quantities primitive wafer deformation and failure are more likely to produce products found. The amount of deformation, while case 3 wafer $+0.00517 \mathrm{~mm}$ in +0.06204 $\mathrm{mm}$ between shows little variation does not happen. Wafer thin film type, but in this study since it is aimed at the development of case 3 is an alternative to laying. Ultrathin wafer $0.07 \mathrm{~mm}$ type aluminum material for the transformation of almost no light on the lift during transfer process may be rid of deformation.
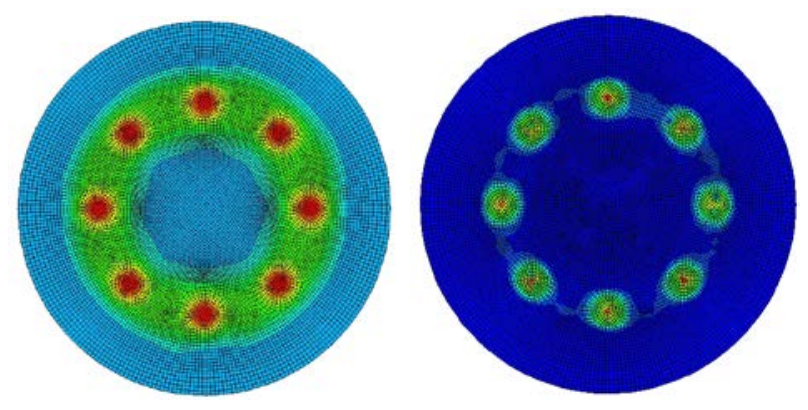

(a) Aluminum (b) silicon

Fig. 14 Wafer displacement analysis by Case (ABAQUS6.6-1)

TABLE 5 WAFER CHUCK AFTER AIR HOLE PRESSURE AND MAXIMUM DISPLACEMENT

\begin{tabular}{|c|c|c|}
\hline & Glass Maximum & Glass Minimum \\
& Displacement [mm] & Displacement [mm] \\
\hline Case1 & 6.912 & 0.6561 \\
\hline Case2 & 0.3825 & 0.03813 \\
\hline Case3 & 0.01401 & 0.001016 \\
\hline
\end{tabular}

As a result, between-0.06465mm +0.01131 mm deformation occurs in almost as small variations will not affect wafer is considered. In addition, the final aim of this study support that hold air and ultra-thin wafer handling expression possible of the waterfront is expected to be realized. Model specifications and transported to the robot's hand because the existing equipment according to specific design that can be embedded in the actual process looks. To reduce the damage of wafer aluminum wafer, place in the form of Case1 and Case3 $0.01401 \mathrm{~mm}$ interpret the results showed that the displacement 
appears. Influence in silicon safer pressure, dude, but its value is very safer can reduce the damage can be determined.

\section{CONCLUSION}

In this paper, contactless wafer handling was used for the air bearing principle wafer defect rate and productivity by reduced damage to secure the flow of technology. Wafer floating with air flow analysis were performed by a variety of design attempting to change the length and width after a through flow analysis and fluid behavior of pressure distribution was conducted on the basis of analytical results due to the pressure exerted on wafer thickness. Also, thinning process according to the displacement process was aimed at commercial. Contactless wafer flow verification through your hand as a non-technical aspects to minimize damage due to contact wafer thinning process and application of process technology in the next generation wafer transfer device as many effects and domestic producers autonomous robot system, the possible increase applies is expected. Thinning process, especially used in ultra-thin wafer transfer from the non-contact state in the freedom movement as possible the structural design and structural analysis performed by hydraulic distribution through car non-contact conditions are not likely to transform the optimal design of the structural model is that hand . But the future of the density and variety of mesh type by analysis of the results with experimental values reveals the need for test

\section{ACKNOWLEDGMENT}

This research was supported by the by the Hoseo University Institute by grant No. 2012-0230.

\section{REFERENCES}

[1] B-S.Kim et al., (2002), "A numerical analysis of the dimensional stability of the plastic composites using a thermoviscoelastic composite using a thermoviscoelastic Journal of composite material, Vol.36, No.20,pp.23892403.

[2] B-S.Kim et al., (2002), "Dimensional stability analysis of themoviscoelastic for EMI shielding using Melamine-Formaldehyde composite materials, Int's Conference on Advances in Structural Engineering and Mechanics(ASEM02).

[3] Ahn,T.K. and Mote Jr., C.D., (1996), "Monitoring and Preventing the Kick-off during Cutting,"California Cedar Product Co.,

[4] Choi, M.K. and Kim, E.K. (2008), "Ultra-Thinned Si Wafer Processing for Wafer Level 3D Packaging" Journal of KWJS, Vol. 26, No. 1,pp12-16.

[5] Syed A. Nasar, (1987), "Linear electric motors : Theory, Design, and Pratical Applications", Prentice-Hall. Inc.

[6] P. C. Sen, (1975),"On linear synchronous motor (LSM) for high speed propulsion", IEEE Transaction on Magnetics, Vol. Mag-11, No.5, September, pp 1484-1486.

[7] In Ho Moon, Sang Joon Cho and Young Kyu Hwang (2005), "Propulsion Force Coefficient of Injection Nozzle Size on Air Levitation Type Wafer Transfer System", Journal of the Semiconductor \& Display Equipment Technology, Vol. 4, No. 1. pp 35-41.

[8] J-K.Won, J-T.Lee and E-S.Lee (2008), "The Study on the Machining Characteristics of $300 \mathrm{~mm}$ Wafer Polishing for Optimal Machining Condition" Transactions of the Korean Society of Machine Tool Engineers, Vol.17 No.2
[9] S-J.Cho, I-H.Moon, D-K.Kim and Y-K.Hwang (2002), "A Study on the Characteristics of Semiconductor Wafer Transportation for Levitation System" Journal of SAREK, pp 1149-1154.

[10] I-H.Moon and Y-K.Hwang. (2006), "Evaluation of a Wafer Transportation Speed for Propulsion Nozzle Array on Air Levitation System" Journal of Mechanical Science and Technology(KSME Int. J.) Vol. 20, No. 9, pp. 1492-1501

\section{Creative Commons Attribution License 4.0 (Attribution 4.0 International, CC BY 4.0)}

This article is published under the terms of the Creative Commons Attribution License 4.0 https://creativecommons.org/licenses/by/4.0/deed.en_US 